\title{
Professional education of the nurse and ethical challenges of the profession
}

\author{
Edison Luiz Devos Barlem ${ }^{1}$
}

Nursing is characterized as a moral practice due to the constant need of taking decisions and making ethical choices, which involve the respect to the rights and the guarantee of the autonomy of the patients, not always identified that their actions or omissions result in significant impact to those with whom the care is developed. There are many factors which make these choices difficult, such as values in conflict or feelings of impotence facing the non-consistent actions with his own consciousness, showing that within the practice of care, the moral motivation is not the only determinant of the actions.

The origin of these difficulties has its start in the professional education, a period of construction of the subjectivity and necessary competences to the future nurses, in which it is possible to observe clear valorization of the practical exercise, of the experience in real scenarios of assistance as priority conditions for the development of those competences. The clinical acting, for example, is developed through its capacities of evaluating, comparing, assessing, in which the eyes are trained to see the imperceptible the eyes of a laymen. The manner as well as the ethics and the moral sensibility which permeate the competences are little explored, neither are they discussed concerning the strategies to enhance/develop their dimensions ${ }^{(1)}$.

The daily situations of the work of nursing and the moral obligations are perceived in a unique manner by the nurses. Regarding the professional practice, it is identified that the organization and the nursing working environment seem to negatively influence the care rendered. So, despite the fact that the nurses recognize the need of provoking questionings facing the problems, they can show to be fearful in doing so, possibly by the unbalance of power experienced in the work environment.

Every day, the nurses deny the ethical dimension of the problems and face the obstacles, underestimating the ways of care actually turned to the interests and needs of the patients. When they become morally committed to take decisions and exercise such care, the nurses can show that they are in a unique position in the relation in health, being able to help the patients and in clarifying the objectives of their treatments and cares as well as in the maintenance of the autonomy and guarantee the quality of assistance, exercising what is conceptualized as patient advocacy ${ }^{(2)}$.

When rescuing the professional education of the nurse and the ethical challenges of the profession, it is observed that there is the urgency to rethink the teaching of ethics in education, in a permanent and inseparable way to all health practices. It is still indispensable to develop, in the future nurses, a potential of moral sensibility which allows to identify that the main role of nursing is inseparably related to the patient advocacy, as a fundamental activity of the kind of nursing which is protagonist in the services of health.

\section{References}

1. Barlem ELD, Ramos FRS. Constructing a theoretical model of moral distress. Nurs Ethics. 2014. In press.

2. Mahlin M. Individual patient advocacy, collective responsibility and activism within professional nursing associations. Nurs Ethics. 2010; 17(2):247-54.

\footnotetext{
${ }^{1}$ Universidade Federal do Rio Grande. Rio Grande, RS, Brazil. 